\title{
Occipitalization of Atlas: A Case Report with its Ontogenic Basis and Review of Literature
}

\author{
${ }^{1}$ Monika Lalit, ${ }^{2}$ Sanjay Piplani, ${ }^{3}$ Anupama Mahajan, ${ }^{4}$ JS Kullar
}

\begin{abstract}
Introduction: Anatomy of the cervical vertebrae allows free flexion, extension, and rotation, which take place almost entirely in the first two cervical vertebrae. Variation in the articulation of upper cervical spine-like congenital fusion of the atlas to the base of the occiput, i.e., occipitalization of the atlas, is one of the common skeletal abnormalities. Such variations will produce irregular motion and at times a definite instability of the joint involved.

Conclusion: Considering the nature and functional importance of the joints in relation to these bones, the resulting disability is one of the rare occurrences and deserves special attention. Such patients exhibit neurological signs and symptoms usually no sooner than the second decade. Thus, anatomy, variations, and anomalies of the craniocervical junction are of high clinical importance to many specialties like anatomists, neurosurgeons, radiologists, and manipulative therapists, as they markedly influence mobility and stability of the cervical region.
\end{abstract}

Keywords: Atlas, Cervical region, Craniovertebral joint, Occipitalization.

How to cite this article: Lalit M, Piplani S, Mahajan A, Kullar JS. Occipitalization of Atlas: A Case Report with its Ontogenic Basis and Review of Literature. Curr Trends Diagn Treat 2017;1(1):34-37.

\section{Source of support: Nil}

Conflict of interest: None

\section{INTRODUCTION}

Occipitalization is the congenital fusion of the atlas to the base of the occipital bone of the skull, an important malformation of the craniovertebral junction because of its proximity to the spinomedullary region. ${ }^{1}$ Atlantooccipital fusion has been extensively dealt with in the literature by various craniologists and also known as

\footnotetext{
${ }^{1}$ Assistant Professor, ${ }^{2,3}$ Professor, ${ }^{4}$ Associate Professor

${ }^{1,3}$ Department of Anatomy, Sri Guru Ram Das Institute of Medical Sciences and Research, Amritsar, Punjab, India

${ }^{2}$ Department of Pathology, Sri Guru Ram Das Institute of Medical Sciences and Research, Amritsar, Punjab, India

${ }^{4}$ Department of Anatomy, Government Medical College, Amritsar Punjab, India

Corresponding Author: Monika Lalit, Assistant Professor Department of Anatomy, Sri Guru Ram Das Institute of Medical Sciences and Research, Amritsar, Punjab, India Phone: +919814325454, e-mail: monika.lalit@yahoo.com
}

occipitocervical synostosis, atlanto-occipital fusion, and atlas assimilation. It was first described by Rokitansky in 1844, and Schuller in 1911 demonstrated this anomaly on roentgen graphically. It was formerly described as "pro-atlas," as it was believed that an additional vertebra was incorporated between the atlas and the occipital bone. ${ }^{2}$ The anomalies pertaining to the occipitocervical junction assume great clinical importance because of the presence of structures like vertebral artery, first cervical nerve, and posterior atlanto-occipital membrane related to posterior arch of atlas vertebra. Compression of these structures may compromise the blood flow to the brain and may cause neurological symptoms and abnormal posture of the head. ${ }^{3}$ Fusion of the atlas with the occipital bone may favor dislocation of the atlas from the dens, or the fusion may be secondary to inflammation set up by the dislocation. ${ }^{4}$ Atlanto-occipital fusion reduces the foramen magnum (FM) dimension resulting in muscle weakness, ataxia, and muscle wasting due to compression of spinal cord or the brain stem. ${ }^{5}$ The onset of clinical symptoms can be sudden and precipitated by minor trauma and may also exist without any typical symptomatological presentation, but sudden death has also been reported in some cases. ${ }^{6}$ Keeping this in mind, we report a case of atlanto-occipital fusion with emphasis on its embryological origin and review of literature.

One such specimen was found in a disarticulated skull in the Department of Anatomy in a tertiary care hospital and medical college, Amritsar. The condition of the bone clearly showed that it was nontraumatic and nonpathological. The specimen showed partial assimilation of the atlas with the occipital bone on the right and left sides.

\section{Manifestation of Atlanto-occipital Assimilation}

- The anterior arch of the atlas along with the anterior tubercle was completely fused with the anterior rim of FM of the occipital bone except for a slit-like opening above the left anterior arch of atlas near the anterior tubercle.

- On the right side, the upper margin of right half of the posterior arch was incompletely fused with the posterior rim of FM with an aperture near the fusion 
of superior articular facet (SAF) with the occipital condyles, whereas on the left side, it was not fused with the posterior rim of FM.

- The posterior tubercle of atlas was missing, which made the posterior arch deficit with serrated margins. Due to nonfusion of right and left posterior arches, a gap was observed toward the right side of midline.

- The SAF of the atlas vertebra was completely fused with the occipital condyles on the right and left sides.

- The specimen showed no fusion of the transverse processes with the occipital bone on both the sides.

- The foramen transversaria (FT) were seen to be incomplete on both the sides.

- The inferior articular surfaces of atlas vertebra were oval in outline on the right side and irregular on the left side and converge anteriorly, directed laterally and downward on both the sides.

- The anteroposterior diameter of the FM was $2.6 \mathrm{~cm}$ and seems to be reduced due to encroachment of the posterior arch. The transverse diameter (TD) was $2.4 \mathrm{~cm}$, and average area was $5.92 \mathrm{~cm}^{2}$. The FM is about $3 \mathrm{~cm}$ wide by $3.5 \mathrm{~cm}$ anteroposteriorly. ${ }^{7}$ Longitudinal diameter of the FM is the distance between basion and opisthion. Transverse diameter of the FM is the maximum distance between two lateral margins. ${ }^{8}$

- Hypoglossal canal was observed on the left side and not on the right side, but instead multiple foramina were noted (Figs 1 and 2).

\section{Phylogenetic and Ontogenetic Basis}

A considerable amount of attention has been drawn by various authors into this fascinating field of phylogenetic and ontogenetic research regarding the atlantooccipital fusion.

- According to Macalister, ${ }^{9}$ two ossification centers appear, one just posterior to each of the lateral mass and transverse process that meet in the middle, posteriorly,

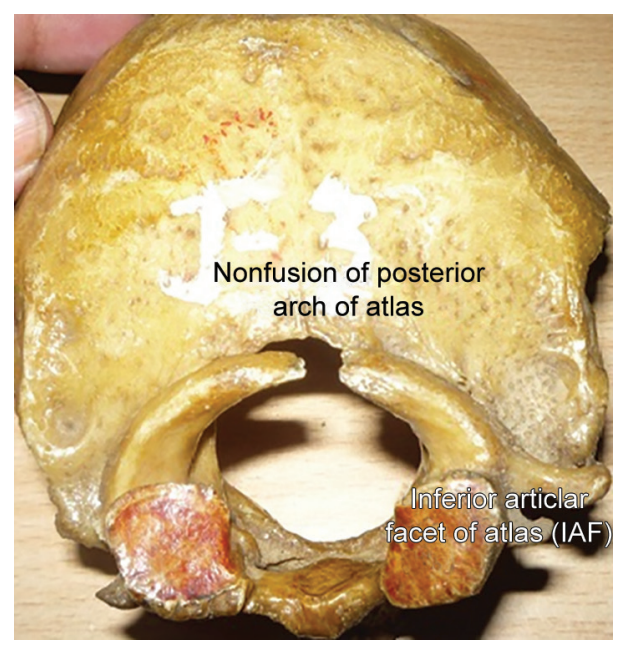

Fig. 1: Superior view showing occipitalization of atlas

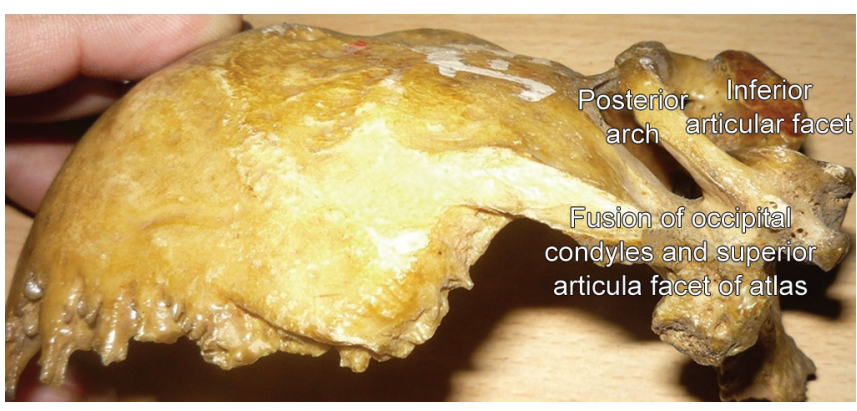

Fig. 2: Lateral view showing occipitalization of atlas

usually by late in the fourth year of life. At about 6 months of age, ossification begins in the anterior part of atlas, generally by two closely approximated ossification centers, which usually unite within a few months of their appearance. Occasionally, there may be a single anterior ossification center. Ossification proceeds posterolaterally along both anterior and posterior arches, and fusion to the lateral masses takes place in the fifth year of life. A midline defect can result from the failure of fusion of the ossification centers either anteriorly or posteriorly.

- The cartilages of the atlas and occipital bone are primarily united by a continuous tissue, characterized by large number of closely set nuclei. In cases of fusion of the atlas, this tissue does not break down to form a diarthrodial joint; thus, there is an arrest of the normal development of the arthrodial joints between the atlas and condyles.

- The atlanto-occipital fusion results from faulty development between the occiput and the adjacent vertebra during the early embryonic weeks. Other malformations, which commonly occur with craniocervical fusion, are pseudo or true basilar impression, absence or malformation of the transverse ligament, hyperplasia of the dens, aplasia of the dens, and anomalies of the vertebral artery due to the absence or malformation of the foramen transversarium. ${ }^{10}$

- The occipital bone is derived from the basioccipital (anterior to FM), exoccipital (lateral to FM), and supraoccipital portions (posterior to FM), laid down in chondrocranium around the FM. ${ }^{11}$ The basiocciput goes on to develop into four occipital sclerotomes. In humans, the cranial half of the first cervical sclerotome fuses with the caudal portion of the fourth occipital sclerotome to form the proatlas; the proatlas is assimilated into the occiput to form the articular condyles and tip of the odontoid process, whereas ${ }^{12}$ in some lower vertebrates (reptiles), the cranial half of the first cervical sclerotome, i.e., the proatlas, between the occiput and $\mathrm{C} 1$ vertebra remains as a separate bone. The caudal half of the first cervical 
sclerotome along with the cranial part of the second cervical sclerotome gives rise to the lateral masses and anterior and posterior arches of atlas vertebra and the odontoid process of the axis. The body disappears early, giving rise to all but the tip of the dens. ${ }^{11} \mathrm{~A}$ paracondylar process represents vestiges of the cranial half of the first cervical sclerotome. This formation is referred to as a caudal shifting, where the occipital vertebra separates from the occiput. ${ }^{12}$ If this normal segmentation fails to occur, atlanto-occipital fusion results. ${ }^{11}$ Thus, the embryological reason for atlantooccipitalization is the failure to differentiate the fused caudal and cranial segments of the 4th occipital and first cervical sclerotome and lack of segmentation and separation between the loose and dense zones of first cervical sclerotome. ${ }^{13}$

\section{DISCUSSION}

Occipitalization represents the most cephalic "blocked" vertebra encountered in the spine. ${ }^{14}$ The incidence of atlanto-occipital fusion ranges from 0.14 to $0.75 \%$ of the population, with both sexes being equally affected. ${ }^{2}$ Fusion of the atlas may be partial or complete, with the former being the most common as multiple variations of partial assimilation have been reported that may involve any aspect of atlanto-occipital articulation. Jayanthi et al ${ }^{5}$ reported two cases of occipitalization with spina bifida of atlas. In the first case, there was complete fusion of only one transverse process with occipital bone and incomplete fusion of the anterior arch. In the second case, the anterior arch of the atlas was fused with the occipital bone. Nayak et $\mathrm{al}{ }^{15}$ reported a case of atlas assimilation showing that the two superior facets on the lateral mass were completely fused with the occipital condyles, and the anterior arch was incompletely fused with the basilar part. The posterior arch was also incomplete and was represented by two small projections from the two lateral masses. Hensinger ${ }^{6}$ reported that the onset of clinical symptoms can be sudden and precipitated by relatively minor trauma, but death has also been reported. Lopez et $\mathrm{a}^{16}$ reported three patients with atlanto-occipital fusion: One had cervical pain and two had tonic or clonic convulsions. Hadley ${ }^{17}$ and Iwata et $\mathrm{al}^{18}$ each reported a case of atlanto-occipital fusion with unusual neurological symptoms. Kussmaul and Tenner ${ }^{19}$ reported three cases with convulsions. Englander ${ }^{20}$ and Albrecht and Castrischer ${ }^{21}$ reported cases with cervical pain, whereas Budin and Sondheimer ${ }^{22}$ reported a patient with cervical pain following hyperextension. Keller ${ }^{23}$ reported a case with seizure disorders. Vakili et al ${ }^{24}$ reported a case of fusion with sudden death.

The assimilation may reduce the FM and lead to neurological complication due to compression of the spinal cord. ${ }^{25}$ According to Greenbery, ${ }^{26}$ spinal cord compression always occurs when the sagittal spinal canal diameter behind the odontoid process is $\leq 14 \mathrm{~mm}$. Cord compression is possible when the sagittal canal diameter is between 15 and $17 \mathrm{~mm}$ and almost never occurs with a diameter of $18 \mathrm{~mm}$ or more. With aging, the central nervous system may be less tolerant to repeated blows from the odontoid. The patient will be probably asymptomatic if the odontoid process is located below the level of FM. This relationship is best assessed through the use of McRae and Barnon line, which is drawn across the FM. It is a radiographic line drawn on a lateral radiograph of skull or sagittal section of computed tomography or magnetic resonance imaging, joining the anterior basion and posterior opisthion aspects of FM. Normal position of tip of dens is $5 \mathrm{~mm}$ below this line. Normally, the odontoid process should not project above this line. If tip of dens migrates above this line, it indicates the presence of basilar invagination, i.e., atlanto-axial impaction. ${ }^{27}$

The skull bone we report here showed that the left lateral mass has been slightly protruding into FM, and TDs have appeared to be reduced.

Although atlanto-occipital fusion is a congenital condition, younger patients are commonly asymptomatic, and the onset of neurological symptoms is usually in the third or fourth decade of life. ${ }^{5}$ This may be due to the instability with aging, gradual increase in the degree of ligamentous laxity about the odontoid process caused by repeated flexion and extension of the neck, leading to the compression of the spinal cord or actual indentation of the medulla oblongata. ${ }^{28}$

According to McRae and Barnon, patients with occipitalization of the atlas may have the physical features like low hairline, torticollis, restricted neck movements, or abnormal short neck. The clinical findings in neurological examination may reveal neck pain, numbness, pain in the limbs, weakness, abnormal head posture, and posteriorly located dull aching headache. Cranial nerve findings associated may include tinnitus, visual disturbances, and lower cranial nerve palsies, leading to dysphagia and dysarthria. ${ }^{27}$ To rule out atlanto-occipital fusion, the mentioned clinical features should be kept in mind as patients with Arnold-Chiari syndrome also present with the same clinical features. ${ }^{29,30}$ Research reports depict that the atlanto-occipital fusion is often associated with bony torticollis, and in the present case, we have found the tilting of atlas toward the right side, thereby giving rise to asymmetry of the skull base.

\section{CONCLUSION}

Thus the knowledge of assimilation may be of importance to neurosurgeons dealing with the neurological complications due to compression of spinal cord, orthopedic 
surgeons dealing with the pathologies of upper cervical spine, and anesthetists dealing with the cause of failure of cisternal puncture. Physiotherapists dealing with neck pain and radiologists dealing with the abnormalities of cervical spine must also be aware of this condition. Transverse process is a very important landmark for head and neck surgeons; when it is inclined and fused to occipital bone, there may be confusion in reaching various structures and may also lead to asymmetry in the shape and structure of apertures for passage of vessels and nerves around the FM. Therefore, the serious consequences of upper cervical manipulation with this type of osseous anomaly reflect the importance and need for a thorough clinical assessment and evaluation on every patient in day-to-day clinical practice.

\section{REFERENCES}

1. Tun K, Okutan O, Kaptanoglu E, Gok B, Solaroglu I, Beskonakli E. Inverted hypertrophy of occipital condyles associated with atlantooccipital fusion and basilar invagination: a case report. Neuroanatomy 2004 Dec;3:43-45.

2. Guebert, G.M.; Yochum, T.R.; Rowe, L.J. Congenital anomalies and normal skeleton variants. In: Yochum, T.R.; Rowe, L.J., editors. Essentials of skeletal radiology. Baltimore, MD: Williams and Wilkins; 1987. p. 197-386.

3. Malhotra V, Leeds NE. Occipitalisation of the atlas with severe cord compression. Skeletal Radiol 1984;12(1):55-58.

4. Dwight T. Concomitant assimilation of the atlas and occiput. Anat Rec 1909 Jun;3(6):321-333.

5. Jayanthi V, Kulkarni R, Kulkarni RN. Atlanto-occipital fusion: report of two cases. J Anat Soc India 2003;52(1):71-73.

6. Hensinger RN. Osseous anomalies of the craniovertebral junction. Spine 1986 May;11(4):323-333.

7. Romanes, G.J. Cunmningham's text book of anatomy. 12th ed. Oxford: Oxford University Press; 1981. p. 114.

8. Routal RR, Pal GP, Bhagwat SS, Tamankar BP. Material studies with sexual dimorphism in foramen magnum of human crania. J Anat Soc India 1984;33(2):85-89.

9. Macalister A. Notes on the development and variations of the atlas. J Anat Physiol 1893 Jul;27(Pt 4):519-554.

10. Grilliot JR, Oswal CA. Assimilation of the atlas and occiput: a case report. J Can Chiropr Assoc 1988 Dec;32(4):195-198.

11. Shapiro R, Robinson F. Embryogenesis of the human occipital bone. Am J Roentgenol 1976 May;126(5):1063-1068.

12. Black S, Scheuer L. Occipitalization of the atlas with reference to its embryological development. Int J Osteoarch 1996;6: 189-194.
13. Motabagani MA, Surendra M. Total occipitalisation of the atlas. Anat Sci Int 2006 Sep;81(3):173-180.

14. Yochum, T.R.; Rowe, L.J. Essentials of skeletal radiology. 2nd ed. Baltimore, MD: William and Wilkins; 1987. p. 1-3.

15. Nayak S, Vollala VR, Raghunathan D. Total fusion of atlas with occipital bone: a case report. Neuroanatomy 2008;4:39-40.

16. Lopez ZA, Limousin LA, Mantz JR. Contribution a la sistematica dc las mal formations del atlas a la luz de una neuva malformation inestable. Rev Clin Espanola 1964;94:208-215.

17. Hadley LA. Atlanto-occipital fusion, ossiculum terminale and occipital vertebra as related to basilar impression with neurological symptoms. Am J Roentgenol Radium Ther 1948 Apr;59(4):511-523.

18. Iwata A, Murata M, Nukina N, Kanazawa I. Foramen magnum syndrome caused by atlanto-occipital assimilation. J Neurol Sci 1998;154:229-231.

19. Kussmaul, A.; Tenner, A. On the nature and origin of epileptiform convulsions caused by profuse bleeding and also of those of true epilepsy. Brunner, E, translator. London: the New Sydenham Society; 1859. p. 109.

20. Englander U. Uber spalt forminge Defekte bzw, Persistierende knorpelfugen in Vorderen Atlasbogen. Fortschr A.D. Gen Rontgnstr 1934;49U:403-406.

21. Albrecht HJ, Castrischer E. Spaltbuilding in vorden and hinteren altasbogen. Fortchr A.D. Gen Rontgenstr 1968;108: 543-545.

22. Budin E, Sondheimer F. Lateral spread of the atlas without fracture. Radiology 1966 Dec;87(6):1095-1098.

23. Keller HL. Formvarianten and fehlbildengen des atlas and seiner umgebung. Fortschr A.D. Gen Roentgenstr 1961;95: 361-370.

24. Vakili ST, Aguilar JC, Muller J. Sudden unexpected death associated with atlanto-occipital fusion. Am J Forensic Med Pathol 1985 Mar;6(1):39-43.

25. Sani V, Singh R, Bandopadhyay M, Tripathi S, Shamal S. Occipitalization of the atlas: its occurrence and embryological basis. Int J Anat Variations 2009;2:65-68.

26. Greenbery AD. Atlanto-axial dislocation. Brain 1968:91(4): 655.

27. McRae DL, Barnon AS. Occipitalisation of atlas. Am J Roentgenol Radium Ther Nucl Med 1953 Jul;70(1):23-46.

28. Bopp A, Frauendorf E. Paracondylar process versus paramastoid process - a contribution to its nomenclature and topographic anatomy. Homo 1996 Jun;47:163-176.

29. Bailey, R.W.; Sherk, H.H.; Don, E.J.; Fielding, J.W.; Martin Long, D.; Uno, K.; Fening, L.; Staufer, E.S. The cervical spine: occipitalization of atlas. Philadelphia, PA: Lippincott; 1983. p. 150.

30. Rajani SJ, Suttarwala IM, Rajani JK. An unusual case of unilateral atlanto-occipital assimilation with skull asymmetry. Nat J Med Res 2012;2(2):238-240. 